\title{
EFECTO DEL SECADO TÉRMICO Y EL TRATAMIENTO ALCALINO EN LAS CARACTERÍSTICAS MICROBIOLÓGICAS Y QUÍMICAS DE BIOSÓLIDOS DE PLANTAS DE TRATAMIENTO DE AGUAS RESIDUALES DOMÉSTICAS
}

\author{
Jorge Silva-Leal*, Diego Bedoya-Rios y Patricia Torres-Lozada \\ Área Ingeniería Sanitaria y Ambiental, Universidad del Valle, A.A 25360, Cali, Colombia
}

Recebido em 21/2/12; aceito em 23/8/12; publicado na web em 24/1/13

\begin{abstract}
EFFECT OF THERMAL DRYING AND ALKALINE TREATMENT ON THE MICROBIOLOGICAL AND CHEMICAL CHARACTERISTICS OF BIOSOLIDS FROM DOMESTIC WASTEWATER TREATMENT PLANTS. We evaluated the effect of thermal drying $\left(60\right.$ to $75{ }^{\circ} \mathrm{C}$ and times from 0 to $\left.12.58 \mathrm{~h}\right)$ and alkaline treatment $\left(\mathrm{Ca}(\mathrm{OH})_{2}\right.$ and $\mathrm{CaO}$ at doses from 8 to $10 \%$.) on the microbiological and chemical characteristics of biosolids from the Cañaveralejo WWTP. The results showed that in thermal drying all temperatures studied were sufficient to achieve the sanitation of biosolids. In the alkaline treatment the two types of lime showed the total elimination of fecal coliforms, E. coli and helminth eggs, however, the process of alkalization of biosolids had significant influences on organic carbon and calcium.
\end{abstract}

Keywords: biosolid; thermal drying; alkaline treatment.

\section{INTRODUCCIÓN}

Los biosólidos son los lodos que pueden ser empleados benéficamente después de ser sometidos a procesos de estabilización como la digestión aerobia o anaerobia, ${ }^{1}$ aunque éstos contienen una importante proporción de elementos fertilizantes de gran valor agronómico, la presencia de microorganismos implica que su aplicación directa sin tratamiento previo represente riesgos para la salud humana y biótica. ${ }^{2}$

Los niveles de microorganismos patógenos, protozoos, parásitos y otros contenidos en los biosólidos, pueden ser significativamente mayores a los presentes en las aguas residuales domésticas; ${ }^{3}$ bacterias indicadoras de contaminación fecal se encuentran presentes en los lodos frescos en concentraciones de $10^{6}$ a $10^{8}$ coliformes totales, $10^{5}$ $10^{7}$ coliformes fecales y $10^{4}$ a $10^{6}$ streptococos fecales. $^{4}$

En 1993 la Environmental Protection Agency (EPA) de los Estados Unidos expidió la norma para el manejo y disposición de lodos y biosólidos generados en el tratamiento de las aguas residuales, ${ }^{5}$ esta norma estableció un precedente importante en cuanto al manejo de lodos y biosólidos, fijando límites de metales pesados, calidad microbiológica y atracción de vectores, además de recomendar tratamientos para su estabilización, de tal forma que puedan cumplir con dichas exigencias. En países como México, Brasil Chile, y Argentina también se ha logrado normatizar el uso y disposición de biosólidos tomando como referencia la norma de la EPA; en la mayoría de estas normas, los biosólidos se clasifican en clases A y B con excepción de la norma Mexicana que introduce una tercera categoría (clase C); la clase A corresponde a biosólidos que pueden utilizarse sin restricción en agricultura incluyendo todos los usos urbanos con contacto público directo; los de clase B pueden ser aplicados con restricciones, para contacto indirecto, revegetación, cultivos de alimentos que se procesen antes de ser consumidos o cobertura en rellenos sanitarios y los de clase $\mathrm{C}$ mostrados en la norma mexicana pueden emplearse para usos forestales o mejoramientos de suelos.

Los lodos de Plantas de Tratamiento de Aguas Residuales-PTAR son generalmente sometidos a los procesos de espesamiento y digestión; sin embargo, debido a que el material digerido (biosólido) aún

*e-mail: jorgesilvaleal@hotmail.com contiene elevados niveles de microorganismos patógenos, se hace necesario implementar tratamientos complementarios de estabilización como el secado térmico y el tratamiento alcalino entre otros. ${ }^{2,6}$

En el secado térmico puede controlarse de manera muy efectiva la temperatura y el tiempo de exposición, presentando un potencial de higienización alto como complemento a la modesta eficiencia en la remoción de patógenos de la digestión anaerobia. ${ }^{7}$ Se ha encontrado que con temperaturas mayores a $45^{\circ} \mathrm{C}$, es posible eliminar de manera considerable bacterias formadoras de esporas como Clostridium perfringens, Bacillus spp y sulfito reductoras, además de eliminar microorganismos de alta persistencia y patogenicidad como los huevos de helmintos. ${ }^{8}$

En 1983 Feachem et al., construyeron la curva de eliminación total por temperatura para diferentes patógenos, ${ }^{4}$ encontrando que los enterovirus y los huevos de ascaris son los microorganismos más dificiles de eliminar teniendo en cuenta la temperatura y el tiempo de exposición. Estos autores recomiendan realizar un tratamiento a $70{ }^{\circ} \mathrm{C}$ por $30 \mathrm{~min}$ para obtener un producto seguro o garantizando una temperatura de $55^{\circ} \mathrm{C}$ por 3 días. Otros autores como Tchobanoglous et al., Andreoli et al. y Piana presentan igualmente regímenes de temperatura y tiempo que aseguran biosólidos virtualmente libres de patógenos que pueden ser empleados para usos sin ningún tipo de restricción. ${ }^{9-11}$

Giraldo y Lozano encontraron que el tratamiento térmico también ejerce un efecto sobre las características fisicoquímicas del biosólido, ${ }^{12}$ generando reducciones importantes en variables como carbono orgánico, nitrógeno, fósforo, entre otros. Sin embargo, los valores residuales posteriores al tratamiento térmico resultan ser comparables a los presentes en abonos orgánicos, por lo que se consideran aprovechables de manera efectiva en reuso agrícola.

Las principales recomendaciones por diversos autores sobre el proceso de secado térmico reportan rangos de temperatura predominante entre $50-75{ }^{\circ} \mathrm{C}$ y los periodos de tiempo pueden variar entre 3 min y 13 días dependiendo del tipo de microorganismo que se quiera eliminar. ${ }^{13-20}$

El tratamiento alcalino es uno de los más empleados para la higienización de los biosólidos; es la estabilización alcalina en la cual una base, normalmente cal, se mezcla con el biosólido para elevar el $\mathrm{pH}$ y destruir la mayor parte de los microorganismos patógenos. ${ }^{21}$ 
Según la EPA el proceso para la reducción significativa de patógenos y la estabilización del biosólido podría lograrse mediante la combinación de dos mecanismos: la elevación del $\mathrm{pH}$ a valores superiores a 12 unidades por un periodo de al menos $72 \mathrm{~h}$ y la elevación de la temperatura a $52{ }^{\circ} \mathrm{C}$ por un periodo de $12 \mathrm{~h}^{3}$

La causa de la inactivación de los microorganismos en el tratamiento alcalino es aún objeto de estudio, algunas investigaciones sugieren que al menos tres factores influencian la inactivación de los microorganismos, la temperatura, el pH y la volatilización de amoniaco. Con relación a las temperaturas alcanzadas en el proceso, éstas se dan por la reacción del alcalinizante con la humedad presente en el biosólido; en este sentido Pecson et al. encontraron que el efecto esterilizador de la temperatura es el que predomina cuando ésta ha alcanzado valores superiores a $\operatorname{los} 55^{\circ} \mathrm{C} ; ;^{15}$ la influencia del cambio de $\mathrm{pH}$ afecta las especies que están presentes en los biosólidos provocando el consecuente efecto sobre las membranas y las estructuras bacterianas. La volatilización de gas amoniaco puede ayudar en la reducción de bacterias como Salmonella. ${ }^{22}$ Así mismo, Méndez et al. indicaron que el amoniaco representa una alternativa de desinfección de biosólidos y que este gas puede utilizarse para hacer más eficiente la estabilización alcalina. ${ }^{23}$

El tratamiento alcalino ha mostrado ser un tratamiento eficiente en la estabilización o higienización de biosólidos incluyendo bacterias indicadoras de contaminación fecal y parásitos como los helmintos. Jiménez et al. evaluaron el tratamiento alcalino con dosis de cal viva de 15 a $40 \%$ en base seca a muestras de 400 a $1000 \mathrm{~g}$ de lodo, alcanzando remociones mínimas y máximas de 3.6 y 9.5 log para coliformes fecales; 3.7 y $7.9 \log$ para Salmonella sp y 0.1 a $1.3 \log$ para huevos de helmintos constituidos en $90 \%$ por el género Ascaris lumbricoides. ${ }^{24} \mathrm{Al}$ final de proceso se obtuvieron lodos estabilizados que cumplieron con los límites para lodos clase A sin restricción según la EPA. ${ }^{5}$

Abu-Orf et al. emplearon el tratamiento alcalino en la eliminación de microorganismos patógenos y en la reducción de olores ofensivos; las dosis empleadas fueron 50, 100 y $200 \mathrm{~g}$ de cal viva por kilogramo de biosólido durante 356 días de seguimiento. Los resultados mostraron una eliminación total de huevos de helmintos (Ascaris lumbricoides), esporas de Clostridium pefringens, reovirus e indicadores como los coliformes fecales, a los 69 días de tratamiento. ${ }^{25}$

Barros et al. evaluaron la estabilización alcalina con cal hidratada de los biosólidos deshidratados de reactores UASB de la PTAR Mangueira en Brasil, con dosis del 30, 40 y 50\% y en un tiempo de 60 días; encontrando reducciones máximas de 6 unidades logarítmicas para los coliformes fecales y eliminación total de huevos de helmintos para la dosis del $50 \% .{ }^{26}$ Estos resultados son similares a los recomendados por Andreoli et al., quienes definen dosis de 30 a $50 \%$ de cal viva para la higienización de los biosólidos. ${ }^{27}$

Torres et al. evaluaron la estabilización alcalina en unidades experimentales de $20 \mathrm{~kg}$ con el biosólido de la PTAR Cañaveralejo (PTAR-C) de la ciudad de Cali-Colombia encontrando que el $\mathrm{pH}$ aumentó a valores superiores a 12 unidades durante el tiempo suficiente para garantizar la reducción de patógenos y parásitos, alcanzando un material clase A con una dosis del $9 \%$ de cal viva o hidratada. ${ }^{28}$ Este estudio evidenció lo reportado por Araque acerca que el tratamiento alcalino permite obtener un producto clase $\mathrm{A}$ según lo recomendado por la EPA sin el necesario cumplimiento del requisito de temperatura $\left(52{ }^{\circ} \mathrm{C} / 12 \mathrm{~h}\right) .{ }^{20}$

En esta investigación se evaluó el efecto del secado térmico y el tratamiento alcalino sobre las características microbiológicas (coliformes fecales y E. coli), parasitológicas y químicas del biosólido de la Planta de Tratamiento de Aguas Residuales de Cañaveralejo PTAR-C Cali, Colombia.

\section{PARTE EXPERIMENTAL}

\section{Materiales y métodos}

Biosólido

El proyecto se realizó en las instalaciones de la PTAR-C, la cual puede operar bajo las modalidades de tratamiento primario convencional (TPC) o avanzado (TPA), cuyos lodos son conducidos a la línea de lodos para su tratamiento, la cual consta de las etapas de espesamiento, digestión anaerobia y deshidratación mecánica en filtros prensa, obteniéndose el biosólido deshidratado que es el sustrato evaluado en este estudio. Estos biosólidos fueron caracterizados de las variables $\mathrm{pH}$ (agua 1:1), carbono orgánico, ${ }^{29}$ nitrógeno total kjeldahl, ${ }^{30}$ nitrógeno amoniacal, ${ }^{31}$ fósforo total, ${ }^{32}$ potasio, calcio, sodio, boro, manganeso, cobre y zinc, ${ }^{31}$ coliformes fecales, E. coli, salmonella $s p,{ }^{33}$ y huevos de helmintos. ${ }^{34}$

\section{Secado térmico}

Las pruebas de tratamiento térmico se realizaron en un horno con un rango de funcionamiento de temperatura de 2 a $200{ }^{\circ} \mathrm{C}$ y una precisión de $2{ }^{\circ} \mathrm{C}$. Las temperaturas evaluadas se tuvieron en cuenta de acuerdo a lo establecido en estudios anteriores como lo reportado por Feachem et al., EPA y Bagge et al.. ${ }^{4,18}$ Estos autores, encontraron que para temperaturas mesofílicas los tiempos requeridos son muy extensos, aumentando los costos en energía requerida y las temperaturas demasiado altas pueden favorecer la volatilización del nitrógeno. ${ }^{35}$ Las temperaturas evaluadas se observan en la Tabla 1.

Tabla 1. Temperaturas y tiempos de proceso tratamiento térmico

\begin{tabular}{ccc}
\hline Tto No. & Temperatura $\left({ }^{\circ} \mathrm{C}\right)$ & Tiempo de proceso $(\mathrm{h})$ \\
\hline Control & Ambiente & 12.58 \\
1 & 60 & 12.58 \\
2 & 65 & 12.58 \\
3 & 70 & 12.58 \\
4 & 75 & 12.58 \\
\hline
\end{tabular}

Todas las temperaturas se evaluaron por duplicado de manera aleatoria; las bandejas se ubicaron con igual cantidad de biosólidos en todos los casos ( $3 \mathrm{~kg}$ ), asegurando que la altura no superara los $4 \mathrm{~cm}$ y una distribución uniforme del material y de la transferencia de calor.

La toma de muestra para la medición de las variables de control y respuesta se hizo integrando sectores de la bandeja para tomar una muestra representativa. Las frecuencias de medición se definieron con base en los estudios reportados por Carrington et al. y Araque y se observan en la Tabla 2.20,36

Tabla 2. Frecuencias de medición de las variables de control y respuesta

\begin{tabular}{lc}
\hline Variable & Frecuencia/Tratamiento térmico \\
\hline Control & \\
pH (unidades) & $0-6$ h: cada $1 \mathrm{~h}$ \\
Humedad (\%) & $6-12.58 \mathrm{~h}:$ cada $2 \mathrm{~h}$ \\
\hline
\end{tabular}

Respuesta

Coliformes fecales (UFC/g)

Mediciones a 0,8 y $12.58 \mathrm{~h}$

E. coli

Huevos de helmintos $(\mathrm{HH} / \mathrm{g})$

Fisicoquímicos (carbono orgánico, nitrógeno total Kjeldahl, nitrógeno amoniacal, fósforo total, potasio y calcio) 


\section{Tratamiento alcalino}

Para el tratamiento alcalino se evaluaron dosis del 8 al 10\%, peso a peso de cal hidratada y cal viva las cuales fueron seleccionadas a partir de estudios previos. ${ }^{22,28}$ Adicionalmente, se conformó un tratamiento control al cual no se le adicionó alcalinizante con el objetivo de monitorear el comportamiento de dicho material. Se conformaron en total 11 tratamientos de $20 \mathrm{~kg}$ con su respectivo duplicado, ubicados aleatoriamente en un diseño de experimentos con un modelo completamente al azar. La Tabla 3 muestra los tratamientos evaluados.

Tabla 3. Tratamientos evaluados en el tratamiento alcalino

\begin{tabular}{ccc}
\hline No. & Material alcalinizante & Proporción alcalinizante \\
\hline 1 y 2 & Control & $0 \%$ \\
3 y 4 & Cal hidratada & $8.0 \%$ \\
5 y 6 & Cal viva & $8.0 \%$ \\
7 y 8 & Cal hidratada & $8.5 \%$ \\
9 y 10 & Cal viva & $8.5 \%$ \\
11 y 12 & Cal hidratada & $9.0 \%$ \\
13 y 14 & Cal viva & $9.0 \%$ \\
15 y 16 & Cal hidratada & $9.5 \%$ \\
17 y 18 & Cal viva & $9.5 \%$ \\
19 y 20 & Cal hidratada & $10 \%$ \\
21 y 22 & Cal viva & $10 \%$ \\
\hline
\end{tabular}

El seguimiento del proceso de estabilización alcalina se realizó durante 13 días, de acuerdo con lo recomendado por otros autores quienes han encontrado eliminación total de microorganismos patógenos entre 5 y 30 días, ${ }^{28,37-39}$ el día 0 fue el día de aplicación del alcalinizante. Para el seguimiento de la influencia de la adición de la cal sobre el mejoramiento de la calidad de los biosólidos, se tomaron muestras de varios puntos de las unidades experimentales para conformar muestras compuestas para el análisis de las variables de control ( $\mathrm{pH}$, temperatura y humedad) y de respuesta (coliformes fecales, salmonella y huevos de helmintos) las cuales se muestran en la Tabla 4.

Tabla 4. Variables evaluadas y frecuencia de medición

\begin{tabular}{|c|c|}
\hline Variable & Frecuencia \\
\hline \multicolumn{2}{|l|}{ Control } \\
\hline pH (unidades) & $\begin{array}{l}\text { Día 0: } 4 \text { mediciones en el día cada } 2 \text { h } \\
\text { durante las primeras } 8 \mathrm{~h} \\
\text { Día } 1 \text { al 3: } 2 \text { mediciones diarias } \\
\text { Día 3-13: } 1 \text { medición diaria }\end{array}$ \\
\hline Temperatura $\left({ }^{\circ} \mathrm{C}\right)$ & $\begin{array}{l}\text { Día 0: } 8 \text { mediciones en el día cada hora } \\
\text { durante las primeras } 8 \mathrm{~h} \\
\text { Día } 1 \text { al 6: } 3 \text { mediciones diarias } \\
\text { Día 7-13: } 1 \text { medición diaria }\end{array}$ \\
\hline Humedad (\%) & Mediciones los días $0,3,5,8,11$ y 13 \\
\hline \multicolumn{2}{|l|}{ Respuesta } \\
\hline Coliformes fecales (UFC/g) & Mediciones los días 0,3 y 13 \\
\hline E. coli & Mediciones los días 0, 3 y 13 \\
\hline Huevos de helmintos $(\mathrm{HH} / \mathrm{g})$ & Mediciones los días 0,3 y 13 \\
\hline
\end{tabular}

Al final del proceso de alcalinización, se realizó una medición de las variables químicas (carbono orgánico, nitrógeno total Kjeldahl, nitrógeno amoniacal, fósforo total, potasio y calcio) con el objetivo de evidenciar el efecto del tratamiento alcalino sobre la calidad del producto final. A los resultados de las variables de control se les realizó análisis de estadística descriptiva y a las variables de respuesta, análisis de varianza asociados al modelo experimental usado.

\section{RESULTADOS Y DISCUSIÓN}

\section{Biosólido}

La Tabla 5 muestra los resultados de la caracterización inicial del biosólido.

Tabla 5. Resultados iniciales de caracterización del biosólido

\begin{tabular}{lccc}
\hline Variable & Unidad & Valor & $\begin{array}{c}\text { Valor de referencia } \\
\text { y concentraciones } \\
\text { límites* }\end{array}$ \\
\hline Fisicoquímico & & & \\
\hline pH & Unidades & $7.1-9.0$ & $5.5-6.4$ \\
Humedad & $\%$ & $64.5-74.2$ & $71.2-82.7$ \\
Carbono orgánico & $\mathrm{g} / \mathrm{kg}$ & 232.6 & $201-382$ \\
Nitrógeno total Kjendhal & $\mathrm{g} / \mathrm{kg}$ & 23.1 & $21.2-42.1$ \\
Nitrógeno amoniacal & $\mathrm{mg} / \mathrm{kg}$ & 2983.8 & $1403-10253 * *$ \\
Fósforo total & $\mathrm{g} / \mathrm{kg}$ & 10.2 & $0.95-26.9$ \\
Potasio & $\mathrm{g} / \mathrm{kg}$ & 0.9 & $0.34-1.0$ \\
Calcio & $\mathrm{g} / \mathrm{kg}$ & 25.5 & $6.6-47.8$ \\
Sodio & $\mathrm{g} / \mathrm{kg}$ & 470.3 & $0.5-2.4$ \\
Boro & $\mathrm{g} / \mathrm{kg}$ & 22.1 & $10.1-29.3$ \\
Manganeso & $\mathrm{g} / \mathrm{kg}$ & 363.9 & $232-425$ \\
Cobre & $\mathrm{g} / \mathrm{kg}$ & 218.1 & $114-953 ;$ \\
& & & $4300 * * *$ \\
Zinc & $\mathrm{g} / \mathrm{kg}$ & 1092.8 & $530-3372 ;$ \\
& & & $7500 * * *$ \\
\hline Microbiológico y Parasitológico & & & $<1 \times 10^{3} *$ \\
\hline Coliformes fecales & $\mathrm{UFC} / \mathrm{g}$ & $1.47 \times 10^{7}$ & - \\
E. coli & $\mathrm{UFC} / \mathrm{g}$ & $9.80 \times 10^{6}$ & $<1$ \\
Salmonella sp & $\mathrm{Ausencia/}$ & $\mathrm{Ausencia}$ & $<3 \mathrm{NMP} / 4$ gramos \\
Huevos de helmintos & $\mathrm{HH} / 4 \mathrm{~g}$ & 4 & $*$ \\
\hline
\end{tabular}

$*$ ref. $40, * *$ ref. $41, * * *$ Concentraciones límites para aplicación agrícola sin restricción (EPA)

Con relación a las variables químicas, este biosólido presenta características similares a las reportadas por Bettiol y Camargo y Dynia et al., para biosólidos de las plantas de tratamiento de aguas residuales de Franca, Barueri, Jundaí, Curitiba y Paranavaí en Brasil, con excepción del $\mathrm{pH}$ y el sodio los cuales fueron mayores en lo encontrado en el biosólido de la PTAR-C; ${ }^{40,41}$ sin embargo, el biosólido de la PTAR-C no presentó ninguna restricción fisicoquímica con base en las concentraciones límites para aplicación agrícola definidas por la EPA. ${ }^{5}$ Las características microbiológicas y parasitológicas mostraron resultados similiares a lo reportado por Guzmán y Campos; Ramírez y Pérez; Araque y Torres et al. para biosólidos deshidratados de plantas de tratamiento de aguas residuales domésticas, mostrando que este material presenta restricciones para su aplicación ya que presentó valores de microorganismos indicadores de contaminación fecal y parasitológicos mayores a lo reportado por la EPA para biosólidos clase A y B, lo que muestra la importancia de tener un proceso para la eliminación de estos microorganismos 
Tabla 6. Comportamiento del $\mathrm{pH}$ durante las pruebas de tratamiento térmico

\begin{tabular}{ccccccccccccc}
\hline Tratamientos/ H & 0 & 1 & 2 & 3 & 4 & 5 & 6 & 8 & 10 & 12,58 \\
\hline Ambiente & & 8,9 & 8.9 & 8,9 & 8.9 & 8,9 & 8,8 & 8,8 & 8,7 & 8,6 \\
60 & & 8,8 & 8,5 & 8,4 & 8,3 & 8,3 & 8,2 & 8,1 & 8,0 & 7,8 \\
65 & 9,0 & 8,7 & 8,6 & 8,4 & 8,3 & 8,3 & 8,1 & 8,0 & 7,9 & 7,8 \\
70 & & 8,3 & 8,2 & 8,1 & 8,1 & 8,0 & 8,0 & 8,0 & 7,5 & 7,0 \\
75 & & 8,6 & 8,4 & 8,1 & 8,0 & 7,9 & 7,8 & 7,8 & 7,1 & 7,0 \\
\hline
\end{tabular}

que permita el aprovechamiento de los biosólidos sin riesgos para el sector agrícola..$^{20,28,42,43}$

\section{Secado térmico}

El comportamiento del $\mathrm{pH}$ se observa en la Tabla 6 .

$\mathrm{El} \mathrm{pH}$ al inicio del proceso fue mayor que lo reportado por Araque y Ramírez y Perez; sin embargo, durante el proceso de secado se presentó una reducción del pH mostrando valores cercanos a la neutralidad..$^{20,43}$ Este comportamiento pudo deberse probablemente al contenido de amoniaco que se une a iones de hidrógeno en presencia de agua para formar el ion amonio, lo que puede producir una disminución del $\mathrm{pH}$ del biosólido. ${ }^{16}$

La Figura 1 muestra los resultados de la humedad durante el proceso de secado térmico.

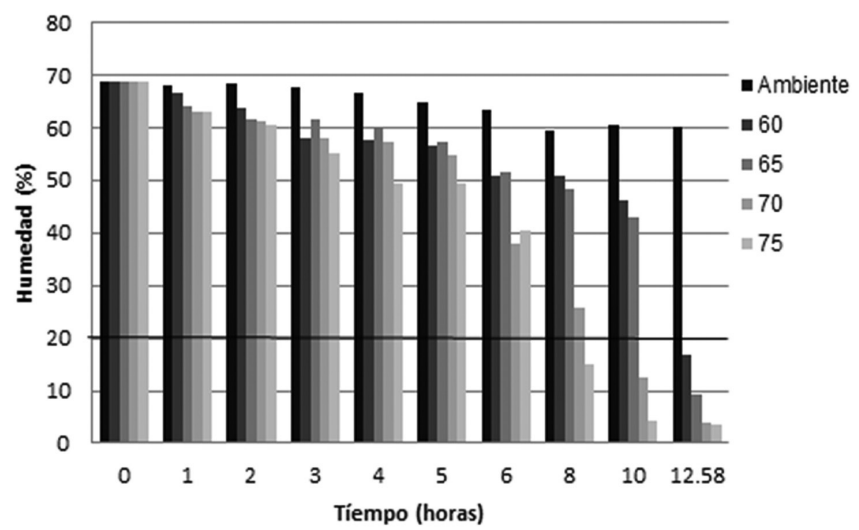

Figura 1. Comportamiento de la humedad durante el tratamiento térmico

En la Figura 1 se observa que para las primeras cinco horas del proceso, los valores de humedad fueron similares para las temperaturas entre 60 y $75{ }^{\circ} \mathrm{C}$ y variaron entre 49 y $58 \%$; a partir de la hora 6 , la diferencia entre tratamientos fue mayor mostrando la influencia del tiempo de secado ya que a mayor temperatura la disminución de humedad fue mayor. Estos resultados son menores a lo encontrado por Giraldo y Lozano quienes mostraron un decaimiento del $65 \%$ de la humedad para un tiempo de proceso entre 3 y $5 \mathrm{~h}$ en un secador directo, ${ }^{12}$ esto debido probablemente al tipo de secado empleado. Teniendo en cuenta lo recomendado por la norma Colombiana NTC 5167,44 donde se recomienda que los productos usados como enmiendas orgánicas deben tener una valor de humedad menor al $20 \%$, se observa que un valor inferior se alcanzó en los tratamientos con tiempos entre $6-8 \mathrm{~h}$ para $75^{\circ} \mathrm{C}, 8$ a10 h para $70{ }^{\circ} \mathrm{C}$ y 10 a $12 \mathrm{~h}$ para 65 y $60{ }^{\circ} \mathrm{C}$.

El comportamiento del contenido de coliformes fecales, E. coli y huevos de helminto durante el proceso de secado térmico se observa en la Tabla 7.

Aunque autores como Avery et al. y Franco-Hernández et al. encontraron una eliminación a temperaturas de $60^{\circ} \mathrm{C}$ en tiempos entre 10 y $30 \mathrm{~min},{ }^{14,17}$ los resultados de este estudio mostraron que en las condiciones en que se realizó, se requiere de tiempos alrededor de 8 $\mathrm{h}$ para temperaturas de 70 y $75^{\circ} \mathrm{C}$ y tiempos entre 8 a $12.58 \mathrm{~h}$ para temperaturas de 60 y $65^{\circ} \mathrm{C}$ para la obtención de biosólido clase A, debido probablemente a que el proceso de pasteurización empleado por estos autores es más eficiente comparado con el secado directo realizado en esta investigación.

Con relación a los valores de huevos de helmintos viables se mostró una eliminación en su totalidad para todas las temperatura evaluadas, corroborando lo propuesto por Carrington et al., quienes aseguraron que el tratamiento térmico a $70^{\circ} \mathrm{C}$ elimina completamente los patógenos considerados de alta resistencia como los huevos de helmintos. ${ }^{45}$ Sin embargo, estos resultados difieren de lo encontrado por Borges et al. quienes reportaron una eliminación total de huevos en $5 \mathrm{~h}$ a una temperatura de $67^{\circ} \mathrm{C} .{ }^{46}$

\section{Tratamiento alcalino}

La Figura 2 muestra el comportamiento de la temperatura en las primeras $8 \mathrm{~h}$ del proceso después de la aplicación del alcalinizante dado que durante los días siguientes los tratamientos presentaron temperaturas similares al tratamiento control.

El tratamiento alcalino presenta un aumento de temperatura en la primera hora del proceso alcanzando una temperatura máxima

Tabla 7. Comportamiento de coliformes fecales, E. coli y huevos de helmintos durante el tratamiento térmico

\begin{tabular}{|c|c|c|c|c|c|c|c|c|c|}
\hline \multirow{3}{*}{$\begin{array}{c}\text { Temperatura } \\
\left({ }^{\circ} \mathrm{C}\right)\end{array}$} & \multicolumn{9}{|c|}{ Tiempo (h) } \\
\hline & \multicolumn{3}{|c|}{0} & \multicolumn{3}{|c|}{8} & \multicolumn{3}{|c|}{12,58} \\
\hline & $\mathrm{CF}$ & E. coli & $\mathrm{HH}$ & $\mathrm{CF}$ & E. coli & $\mathrm{HH}$ & $\mathrm{CF}$ & E. coli & $\mathrm{HH}$ \\
\hline Ambiente & & & & $2,01 \times 10^{6}$ & $1.01 \times 10^{6}$ & 4 & $7.10 \times 10^{5}$ & $5.66 \times 10^{5}$ & 4 \\
\hline 60 & & & & $2,68 \times 10^{4}$ & $2,28 \times 10^{4}$ & 2 & ND & ND & ND \\
\hline 65 & $1,47 \times 10^{7}$ & $9,80 \times 10^{6}$ & 4 & 1500 & 300 & 2 & ND & ND & ND \\
\hline 70 & & & & 50 & ND & ND & ND & ND & ND \\
\hline 75 & & & & ND & ND & ND & ND & ND & ND \\
\hline
\end{tabular}

CF: Coliformes fecales, HH: huevos de helmintos viables. ND: No Detectad 


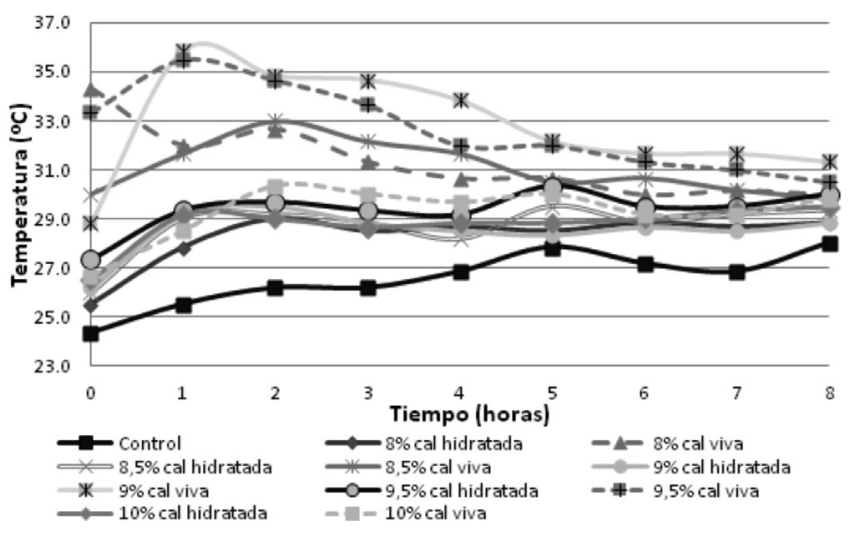

Figura 2. Variaciones de la temperatura durante el tratamiento alcalino

de $35.9^{\circ} \mathrm{C}$, obtenida para el tratamiento $9 \%$ con cal viva; después del primer día del proceso, la temperatura tiende a ser similar al tratamiento control; adicionalmente, se lograron aumentos de temperatura entre 8 y $14.7^{\circ} \mathrm{C}$ con relación al tratamiento testigo. En general los tratamientos con cal viva $(\mathrm{CaO})$ presentaron el mayor aumento de la temperatura, debido a la reacción de la cal viva con la humedad del biosólido que aumentan la temperatura y causan la liberación de gases; este comportamiento mostró resultados similares a lo reportado por Torres et al., y mejores resultados que los encontrados por Araque quien encontró temperaturas de $30{ }^{\circ} \mathrm{C}$ para una dosis de $25 \%$ de cal viva, ${ }^{20,28}$ estos bajos aumentos de temperatura pudieron estar afectados por la mezcla del material. Sin embargo, estos resultados son mejores que los reportados por Barros et al. y Andreoli et al., quienes consiguieron un higienización de los biosólidos con dosis del $50 \%$. $^{26,27}$

La Tabla 8 muestra los resultados de la humedad durante el tratamiento alcalino.

Con relación a la humedad, los resultados mostraron que se mantuvo dentro de un rango de 57 y $64 \%$ lo que indica que no hubo una gran disminución de este parámetro durante el ensayo, mostrando que las bajas temperaturas del proceso no permitieron la liberación de vapor de agua. Adicionalmente, los valores de humedad finales no cumplieron con lo recomendado por la norma NTC $5167,{ }^{44}$ ya que ningún tratamiento alcanzó valores de humedad menores o iguales a $20 \%$.

Las altas humedades finales superiores a $50 \%$ podrían promover el recrecimiento de microorganismos, ${ }^{36}$ y por lo tanto, la inactivación de microorganismos patógenos del proceso se da por otros factores
Tabla 8. Variaciones promedio de la humedad durante el tratamiento alcalino

\begin{tabular}{lcccccc}
\hline Día & $0 *$ & 3 & 6 & 8 & 11 & 13 \\
\hline Control & 69 & 68 & 66 & 65 & 64 & 64 \\
Hidratada 8\% & 64 & 63 & 62 & 62 & 61 & 61 \\
Viva 8\% & 63 & 60 & 60 & 60 & 60 & 59 \\
Hidratada 8,5\% & 62 & 61 & 60 & 61 & 61 & 60 \\
Viva 8,5\% & 62 & 60 & 60 & 59 & 59 & 59 \\
Hidratada 9\% & 63 & 61 & 61 & 62 & 60 & 60 \\
Viva 9\% & 63 & 59 & 58 & 58 & 57 & 57 \\
Hidratada 9,5\% & 62 & 60 & 60 & 60 & 60 & 59 \\
Viva 9,5\% & 63 & 59 & 59 & 59 & 58 & 57 \\
Hidratada 10\% & 62 & 61 & 60 & 60 & 60 & 60 \\
Viva 10\% & 61 & 60 & 61 & 59 & 59 & 59 \\
\hline
\end{tabular}

*Corresponde al momento de la mezcla del alcalinizante con el biosólido

como el sostenimiento del $\mathrm{pH}$ elevado o la formación de productos biocidas como el amoniaco. ${ }^{15}$

Con relación al pH el tratamiento control varió entre 7.9 y 9.4 unidades durante todo el proceso y los tratamientos con cal hidratada mostraron un menor poder alcalinizante comparado con la cal viva, lo que se vio reflejado en que dosis menores de $9 \%$ no garantizaran un $\mathrm{pH}$ mayor a 12 unidades por al menos las horas que recomienda la $\mathrm{EPA}^{3}$ para eliminación de microorganismos patógenos. La Figura 3 muestra el diagrama de boxplot de los valores de $\mathrm{pH}$.

La Figura 3 muestra que las dosis de cal empleadas permiten un aumento del $\mathrm{pH}$ con relación a los testigos, con valores alrededor de 12 unidades, adicionalmente, el tratamiento con dosis de $9 \%$ de cal viva presenta las menores variaciones de valor de $\mathrm{pH}$ y el $75 \%$ de las mediciones se encontraron por encima de las 12 unidades durante los 13 días de ensayo mostrándose como un porcentaje apropiado para la reducción de indicadores de contaminación fecal, corroborando lo encontrado por Torres et al..$^{28}$ En la Tabla 9 se observa los días de permanencia del $\mathrm{pH}$ mayor a 12 unidades del proceso de tratamiento alcalino

En el caso de las dosis 9 y $9.5 \%$ de cal hidratada fue necesario que el proceso permaneciera 11 días para cumplir el criterio de la EPA y garantizar un $\mathrm{pH}$ mayor a 12 por 72 h (días del 9 a 11); la dosis $10 \%$ requirió un tiempo de contacto con el biosólido de 7 días (días del 5 a 7). Los tratamientos con cal viva mostraron que con dosis superiores a $8 \%$ con un tiempo de 10 días se cumple el requerimiento de las 72

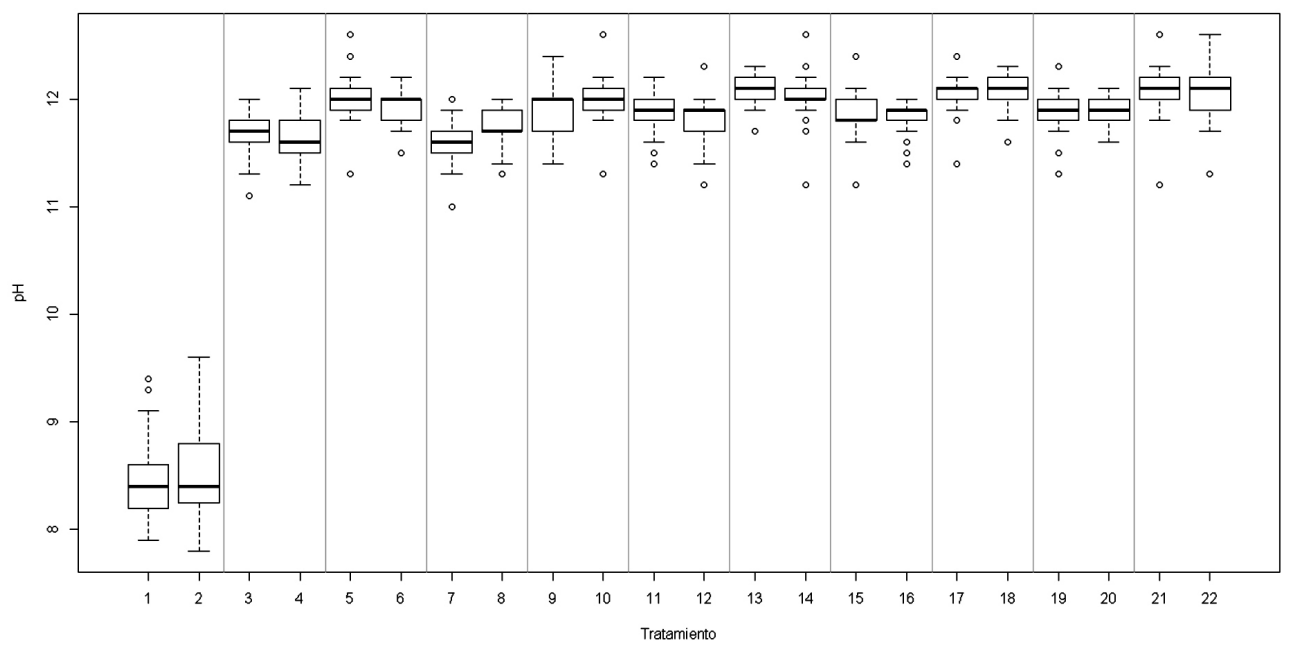

Figura 3. Gráfica de boxplot del comportamiento del pH en el tratamiento alcalino 
Tabla 9. Días de permanencia del pH mayor a 12 unidades

\begin{tabular}{|c|c|c|c|c|c|c|c|c|c|c|c|c|c|}
\hline \multirow[b]{2}{*}{ Tratamiento } & \multicolumn{13}{|c|}{ Días del proceso } \\
\hline & 1 & 2 & 3 & 4 & 5 & 6 & 7 & 8 & 9 & 10 & 11 & 12 & 13 \\
\hline \multicolumn{14}{|l|}{ Control } \\
\hline \multicolumn{14}{|l|}{ Hidratada $8 \%$} \\
\hline Viva $8 \%$ & & & $\mathrm{X}$ & & $\mathrm{X}$ & $\mathrm{X}$ & & $\mathrm{X}$ & $\mathrm{X}$ & $\mathrm{X}$ & $\mathrm{X}$ & & \\
\hline \multicolumn{14}{|l|}{ Hidratada $8,5 \%$} \\
\hline Viva $8,5 \%$ & & & $\mathrm{X}$ & & $\mathrm{X}$ & $\mathrm{X}$ & $\mathrm{X}$ & $\mathrm{X}$ & $\mathrm{X}$ & $\mathrm{X}$ & $\mathrm{X}$ & & $\mathrm{X}$ \\
\hline Hidratada 9\% & & & & & & & $\mathrm{X}$ & & $\mathrm{X}$ & $\mathrm{X}$ & $\mathrm{X}$ & & \\
\hline Viva $9 \%$ & & & $\mathrm{X}$ & $\mathrm{X}$ & $\mathrm{X}$ & $\mathrm{X}$ & $\mathrm{X}$ & $\mathrm{X}$ & $\mathrm{X}$ & $\mathrm{X}$ & $\mathrm{X}$ & & $\mathrm{X}$ \\
\hline Hidratada $9,5 \%$ & & & & & $\mathrm{X}$ & & & & $X$ & $\mathrm{X}$ & $\mathrm{X}$ & & \\
\hline Viva $9,5 \%$ & & $\mathrm{X}$ & $\mathrm{X}$ & $\mathrm{X}$ & $\mathrm{X}$ & $\mathrm{X}$ & $\mathrm{X}$ & $\mathrm{X}$ & $\mathrm{X}$ & $\mathrm{X}$ & $\mathrm{X}$ & & \\
\hline Hidratada $10 \%$ & & & & & $\mathrm{X}$ & $\mathrm{X}$ & $\mathrm{X}$ & $\mathrm{X}$ & $\mathrm{X}$ & $\mathrm{X}$ & & & \\
\hline Viva $10 \%$ & & $\mathrm{X}$ & $\mathrm{X}$ & $\mathrm{X}$ & $\mathrm{X}$ & $\mathrm{X}$ & $\mathrm{X}$ & $\mathrm{X}$ & $\mathrm{X}$ & $\mathrm{X}$ & $\mathrm{X}$ & $\mathrm{X}$ & $\mathrm{X}$ \\
\hline
\end{tabular}

h con un $\mathrm{pH}$ superior a 12 unidades para las dosis $8.5 \%$ (7 días), $9 \%$ (5 días), 9.5 y $10 \%$ (4 días).

La Tabla 10 muestra los resultados de coliformes fecales, E. coli huevos de helmintos y salmonella en el tratamiento alcalino.

Los resultados muestran que todas las dosis usadas lograron una reducción total de coliformes fecales y $E$. coli desde el día 0 correspondiente al momento de la mezcla del biosólido con el alcalinizante; sin embargo, los huevos de helmintos solo se logaron remover entre 0 y 3 días del proceso. Según Pecson et al., con temperaturas inferiores a los $55^{\circ} \mathrm{C}$ como las alcanzadas durante el tratamiento alcalino, los principales factores que actúan en la eliminación de los microorganismos son la elevación del $\mathrm{pH}$ y la formación de gases como el amoniaco que ejercen un efecto bactericida. ${ }^{15}$

Estos resultados muestran que aunque los tratamientos no logren la permanencia del $\mathrm{pH}$ mayor a 12 unidades por $72 \mathrm{~h}$ y no cumplan el requisito de temperatura $52{ }^{\circ} \mathrm{C}$ por $12 \mathrm{~h}$, se puede obtener un biosólido clase A que no genera riesgo de microorganismos patógenos.

Los resultados fisicoquímicos finales para el secado térmico mostraron que no hubo diferencias significativas para las variables de carbono orgánico $(d f=3, F=1.66, p=0.272)$, nitrógeno total Kjeldahl $(d f=3, F=4.49, p=0.056)$ y nitrógeno amoniacal $(d f=$ 3, $F=15.08, p=0.06$ ) de las temperaturas evaluadas con relación al tratamiento control. Adicionalmente el análisis estadístico mostró que el tiempo del secado térmico $(d f=2, F=4.01, p=0.078)$ tampoco tiene un efecto significativo en las variables al final del proceso. Estos resultados muestran que las condiciones evaluadas del secado térmico no afectan las características fisicoquímicas del biosólido al final del proceso. La Tabla 11 muestra los resultados de las variables fisicoquímicas al final del secado térmico y el tratamiento alcalino.

El análisis estadístico del proceso alcalino mostró que éste tiene un efecto significativo en el carbono orgánico $(\mathrm{gl}=1, \mathrm{~F}=11.76, \mathrm{p}=$ 0.006 ) y calcio $(g l=1, F=6.48, p=0.027)$ los cuales se afectaron significativamente por la aplicación del alcalinizante. Sin embargo, en las variables de nitrógeno total $(g l=1, F=3.39, p=0.092)$ y nitrógeno amoniacal $(g l=1, F=1.51, p=0.245)$ este proceso no presentó un efecto significativo al final. Adicionalmente, los resultados muestran pérdidas de carbono orgánico entre el 9-19\% de nitrógeno total Kjeldahl entre el 23-33\% y de nitrógeno amoniacal entre $80-91 \%$ con relación al tratamiento testigo.

De acuerdo con lo reportado Méndez et al., el aumento del pH y la temperatura son la principal causa de volatilización de nitrógeno amoniacal ${ }^{23}$ los resultados del tratamiento alcalino evidenciaron que en este caso el aumento de $\mathrm{pH}$ fue la principal causa en la pérdida de nitrógeno ya que al comparar el tratamiento alcalino con el secado térmico las pérdidas de nitrógeno amoniacal en este último fueron mucho menores que las del tratamiento alcalino, entre 13 y $26 \%$,

Tabla 10. Valores de coliformes fecales, E. coli y huevos de helmintos durante el tratamiento alcalino

\begin{tabular}{|c|c|c|c|c|c|c|c|c|c|}
\hline \multirow{2}{*}{$\begin{array}{l}\text { Día } \\
\text { Tratamiento }\end{array}$} & \multicolumn{3}{|c|}{$0 *$} & \multicolumn{3}{|c|}{3} & \multicolumn{3}{|c|}{13} \\
\hline & $\mathrm{CF}^{* *}$ & E. coli & $\mathrm{HH}$ & $\mathrm{CF}$ & E. coli & $\mathrm{HH}$ & $\mathrm{CF}$ & E. coli & $\mathrm{HH}$ \\
\hline Control & $1,47 \times 10^{7}$ & $9,80 \times 10^{6}$ & 4 & $2.50 \times 10^{6}$ & $3.00 \times 10^{6}$ & 2 & $5.00 \times 10^{5}$ & $1.80 \times 10^{5}$ & 1 \\
\hline $8 \%$ cal hidratada & ND & ND & 2 & ND & ND & ND & ND & ND & ND \\
\hline $8 \%$ cal viva & ND & ND & $\mathrm{ND}$ & ND & ND & ND & ND & ND & ND \\
\hline $8,5 \%$ cal hidratada & ND & ND & 1 & ND & ND & ND & ND & ND & ND \\
\hline $8,5 \%$ cal viva & ND & ND & ND & ND & ND & ND & ND & ND & ND \\
\hline $9 \%$ cal hidratada & ND & ND & ND & ND & ND & ND & ND & ND & ND \\
\hline $9 \%$ cal viva & ND & ND & $\mathrm{ND}$ & ND & ND & ND & ND & ND & ND \\
\hline $9,5 \%$ cal hidratada & ND & ND & ND & ND & ND & ND & ND & ND & ND \\
\hline $9,5 \%$ cal viva & ND & ND & $\mathrm{ND}$ & ND & ND & ND & ND & ND & ND \\
\hline $10 \%$ cal hidratada & ND & ND & $\mathrm{ND}$ & ND & ND & ND & ND & ND & ND \\
\hline $10 \%$ cal viva & ND & ND & ND & ND & ND & ND & ND & ND & ND \\
\hline
\end{tabular}

*Corresponde al momento de la mezcla del alcalinizante con el biosólido. **CF: Coliformes fecales, ND: No Detectado 
Tabla 11. Características fisicoquímicas del biosólido al finalizar los tratamientos

\begin{tabular}{|c|c|c|c|c|c|c|}
\hline Descripción & $\begin{array}{c}\text { Carbono orgánico } \\
(\mathrm{g} / \mathrm{kg})\end{array}$ & $\begin{array}{l}\text { Nitrógeno total Kjel- } \\
\text { dahl }(\mathrm{g} / \mathrm{kg})\end{array}$ & $\begin{array}{l}\mathrm{N}-\mathrm{NH}_{4}^{+} \\
(\mathrm{mg} / \mathrm{kg})\end{array}$ & $\begin{array}{l}\text { Fósforo total } \\
\qquad(\mathrm{g} / \mathrm{kg})\end{array}$ & $\begin{array}{c}\text { Potasio } \\
(\mathrm{g} / \mathrm{kg})\end{array}$ & $\begin{array}{l}\text { Calcio } \\
(\mathrm{g} / \mathrm{kg})\end{array}$ \\
\hline \multicolumn{7}{|c|}{ Tratamiento térmico } \\
\hline Control* & 232,6 & 23,1 & 2983,8 & 10,2 & 0,89 & 25,5 \\
\hline T60-8 h & 257.2 & 21.8 & 2437.1 & 8.9 & 0.92 & 24.5 \\
\hline $\mathrm{T} 65-8 \mathrm{~h}$ & 247.2 & 24.8 & 2474.8 & 11.2 & 0.88 & 24.6 \\
\hline T70-8 h & 235.6 & 24.1 & 2707.7 & 10.8 & 0.92 & 24.3 \\
\hline $\mathrm{T} 75-8 \mathrm{~h}$ & 222.6 & 25.8 & 2216.9 & 11.4 & 0.85 & 24.4 \\
\hline Amb-12.58** & 231.3 & 24.5 & 2464.0 & 10.6 & 0.87 & 21.3 \\
\hline $\mathrm{T} 60-12.58 \mathrm{~h}$ & 212.0 & 24.0 & 2492.9 & 9.9 & 0.91 & 24.8 \\
\hline $\mathrm{T} 65-12.58 \mathrm{~h}$ & 247.1 & 25.2 & 2235.5 & 11.1 & 0.93 & 26.1 \\
\hline $\mathrm{T} 70-12.58 \mathrm{~h}$ & 214.8 & 25.5 & 2573.1 & 11.0 & 0.93 & 25.2 \\
\hline $\mathrm{T} 75-12.58 \mathrm{~h}$ & 214.6 & 24.6 & 2193.5 & 11.4 & 0.91 & 26.1 \\
\hline \multicolumn{7}{|c|}{ Tratamiento alcalino } \\
\hline Control $^{* * *}$ & 248,4 & 22,1 & 982,2 & 15,4 & 1,0 & 31,3 \\
\hline Hidratada $8 \%$ & 207,7 & 15,2 & 196,4 & 11,8 & 0,8 & 107,9 \\
\hline Viva $8 \%$ & 215,5 & 16,4 & 112,5 & 10,7 & 0,8 & 114,5 \\
\hline Hidratada $8.5 \%$ & 224,1 & 15,6 & 113,8 & 11,2 & 0,7 & 119,2 \\
\hline Viva $8.5 \%$ & 208,8 & 14,3 & 181,0 & 9,9 & 0,8 & 111,3 \\
\hline Hidratada $9 \%$ & 212,7 & 14,7 & 118,3 & 9,3 & 0,7 & 126,3 \\
\hline Viva $9 \%$ & 191,7 & 14,7 & 85,6 & 10,5 & 0,8 & 119,7 \\
\hline Hidratada $9.5 \%$ & 207,7 & 14,7 & 110,4 & 10,2 & 0,7 & 125,5 \\
\hline Viva $9.5 \%$ & 202,1 & 14,7 & 153,3 & 10,1 & 0,8 & 116,1 \\
\hline Hidratada $10 \%$ & 199,7 & 15,7 & 107,0 & 10,1 & 0,7 & 104,0 \\
\hline Viva $10 \%$ & 217,6 & 16,5 & 125,2 & 10,0 & 0,7 & 133,2 \\
\hline
\end{tabular}

*Corresponde al tratamiento control (biosólido) al inicio del proceso de secado térmico; **corresponde al tratamiento control (biosólido) secado a temperatura ambiente a las $12.58 \mathrm{~h}$; ***corresponde al tratamiento control (biosólido) sin aplicación de alcalinizante a los 13 días del proceso

demostrando que la temperatura no afectó significativamente este parámetro.

Con relación al contenido de calcio, en el proceso alcalino se observa que la aplicación de hidróxido de calcio y oxido de calcio mostró un aumento del contenido de este elemento al final de proceso, lo que puede ocasionar algunos efectos negativos en el suelo como la reducción de la disponibilidad de otros elementos como fósforo, zinc, boro, hierro, manganeso y cobre, ${ }^{47}$ por lo que se hace necesario controlar este elemento en el suelo cuando se realicen aplicaciones del biosólido alcalinizado.

\section{CONCLUSIONES}

Los biosólidos de la Planta de Tratamiento de Aguas Residuales de Cañaveralejo- Cali Colombia presentan restricciones para su aprovechamiento agrícola desde el punto de vista de la presencia de microorganismos indicadores de contaminación fecal, lo que muestra la necesidad de aplicar procesos adicionales para la reducción de patógenos, siendo el secado térmico y el tratamiento alcalino procesos altamente eficientes para la eliminación total de microorganismos indicadores de contaminación fecal para la escala evaluada. En el secado térmico se pueden emplear las temperaturas $60,65,70$ y 75 ${ }^{\circ} \mathrm{C}$ en un tiempo entre 8 y $12.58 \mathrm{~h}$, rangos en los cuales se conserva el contenido de nutrientes de los biosólidos y se reduce el riesgo asociado al contenido de coliformes fecales, E. coli y huevos de helmintos. El tratamiento alcalino mostró que el uso de cal viva en dosis mayores al $9 \%$ con tiempo de contacto de 5 días es altamente eficiente en el proceso de eliminación de coliformes fecales, E. coli y huevos de helmintos; sin embargo, el proceso de alcalinización de los biosólidos afectó significativamente las variables carbono orgánico y calcio y reduce el contenido de nitrógeno total y amoniacal.

\section{AGRADECIMIENTOS}

Los autores agradecen a Colciencias y a la Universidad del Valle por su apoyo financiero en el proyecto código 1106-489-25147, y la financiación de los estudiantes J. Silva-Leal como becario de doctorado nacional y Diego F. Bedoya-Rios como joven investigador.

\section{REFERENCIAS}

1. WEF - Water Environment Federation; Biosolids Composting, Special Publication: Alexandria, 1998.

2. Kiely, G.; Ingeniería ambiental. Fundamentos, tecnologías y sistemas de gestión, Mac Graw Hill: España, 1999, vols. I, II y III.

3. EPA - Environmental Protection Agency; Control of patogens and vector attraction in sewage sludge under 40 CFR part 503, Office of Water/Office Sciense and tecnology Sludge/Risk Assessment Branch: Washington, 2003.

4. Feachem, R.; Bradley, D.; Garelick, H.; Health aspects of excreta and waste management, John Wiley and Sons: Chichester, 1983.

5. EPA - Environmental Protection Agency; Land Application of Sewage 
Sludge A Guide for Land Appliers on the Requirements of the Federal Standards for the Use or Disposal of Sewage Sludge, 40 CFR Part 503, Office of Water/Office Sciense and tecnology Sludge/Risk Assessment Branch: Washington, 1993.

6. EPA - Environmental Protection Agency; Biosolids generation, use, and disposal in the United States, Office of Solid Waste: Washington, 1999.

7. Almeida, G.; Fanhani, C. J.; D’Oliveiras, S. P.; Dias-Filho, P. B.; Cesumar 2006, 8, 95.

8. Gantzer, C.; Water Res. 2001, 35, 3763.

9. Tchobanoglous, G.; Theisen, H.; Vigil, S.; Integrated solid waste management Engineering Principles and Management issues, McGrawHill: New York, 1993.

10. Andreoli, C. V.; Lara, A. I.; Fernades, F.; Reciclagem de biossólidos. Tranformando problemas em soluções, Companhia de Saneamento do Paraná, Ministério de Ciência e Tecnologia, FINEP, CNPq e CAPES, Curitiba, 1999.

11. Piana, G. M.; Trabalho de graduação, Universidade Federal de Santa Catarina, Florianópolis, 2009.

12. Giraldo, O.; Lozano, A.; Rev. Agro. Col. 2006, 24, 348.

13. Comparini, J. B,; Sobrinho, P. A.; Federación Méxicana de Ingeniería Sanitaria y Ciencias Ambientales, AIDIS; FEMISCA, 2002.

14. Avery, L. A.; Williams, P.; Killham, K; Jones, D.; Bioresour. Technol. 2009, 100, 2692.

15. Pecson, B. M.; Barrios, J. A.; Jiménez, J. A.; Nelson, K. L.; Water Res. 2007, 41, 2893.

16. Sidhu, J. ; Toze, S. G.; Environ. Int. 2009, 35, 187.

17. Franco-Hernández, O.; McKelligan-González, A. N.; López-Olguín, A. M.; Espinosa-Ceron, E.; Escamilla-Silva, E.; Dendooven. L.; Bioresour. Technol. 2003, 87, 93.

18. Bagge, E.; Sahlström, L.; Albihn, A.; Water Res. 2005, 39, 4879.

19. Lang, L.; Stephen, R.; Water Res. 2008, 42, 2229.

20. Araque, M. P.; Tesis Maestría en ingeniería ambiental, Universidad de los Andes, Colombia, 2006.

21. Fernandes, F.; De Souza, S.; Resíduos sólidos do saneamento; Processamento, reciclagem e disposição final, ABES e PROSAB: Rio de Janeiro, 2001, cap. 2.

22. Toze, S.; Sidhu, J.; Encyclopedia of Environmental Health 2011, p. 394.

23. Méndez, J. M.; Jiménez, B. E.; Salgado, G. V.; Congreso Interamericano de Ingeniería Sanitaria y Ambiental, Cancún, México, 2002.

24. Jiménez, B.; Barrios, J. A.; Maya, C.; Water Sci. Technol. 2000, 42, 103.

25. Abu-Orf, M. M.; Brewster, J.; Oleszkiewicz, J.; Reimers, R. S.; Lagasse, P.; Amy, B.; Glindemann, D.; Water Sci. Technol. 2004, 49, 131.

26. Barros, K. K.; Florencio, L.; Takayuki, M. K.; Gavazza, S.; $23^{\circ}$ Congresso Brasileiro de Engenharia Sanitária e Ambiental, Campo Grande, Brasil, 2005.
27. Andreoli, C. V.; De Lara, A. I.; Ferreira, A. C.; Pegorini, E. S.; Ilhenfeld, R. G. K.; Uso e Manejo do Lodo de Esgoto na Agricultura - PROSAB-SANEPAR, FINEP: Rio de Janeiro, 1999.

28. Torres, P.; Madera, C.; Silva, J. A.; Rev. Esc. Ing. Antioquia-EIA 2009, $11,21$.

29. Walkley, A.; Black, I. A.; Soil Sci. 1934, 63, 251.

30. Kjeldahl, J.; Anal. Chem. 1883, 22, 366.

31. USDA - United States Department of Agriculture, NRCS - Natural Resources Conservation Service; Soil Survey Laboratory. Methods Manual, Soil Survey Investigations Report No. 42, 2004.

32. Bray, R. H.; Kurtz, L. T.; Soil Sci. 1945, 59, 39.

33. American Public Health Association (APHA), American Water Works Association (AWWA); Water Environment Federation (WEF); Standard Methods for the Examination of Waters and Wastewaters, 21th ed., APHA, AWWA, WPFC, Washington, 2005.

34. Bailinger, J.; J. Am. Med. Technol. 1979, 41, 65.

35. Salvagiotti, F.; Cuantificación de las pérdidas de nitrógeno por volatilización y su efecto en el rendimiento del cultivo de maíz, EEA INTA: Oliveros, 2004.

36. Carrington, E. G.; European Commission report no. CO 5026, no. 1, 2001.

37. Boost, M. V.; Poon, C. S.; Environ. Int. 1998, 24, 783.

38. Madera, C.; Peña, M.; Mara, D.; Muñoz, N.; Conference Waste Stabilisation Ponds: Pond Technology for the New Millennium, Nueva Zelanda, 2002.

39. Placha', I.; Venglovský, J.; Maková, Z.; Martinez, J.; Bioresour. Technol. 2008, 9, 4269.

40. Bettiol, W.; Camargo, O.; Lodo de esgoto impactos ambientais na agricultura, Empresa Brasileira de Pesquisa Agropecuária: falta cidade, $2^{\mathrm{a}}$ ed., 2008, cap. 2.

41. Dynia, J. F.; Boeira, R. C.; de Souza, M. D. Em ref. 40, cap. 5.

42. Guzmán, C.; Campos. C.; Univ. Sci. 2004, 9, 59.

43. Ramírez, P. R.; Pérez, A. M.; Rev. Fac. Nal. Agr. Medellín 2006, 59, 3543.

44. Icontec, Norma Técnica Colombiana NTC 5167; Productos para la industria agrícola y materiales usados como fertilizantes y acondicionadores, 2003.

45. Carrington, E. G.; Davis, R. D.; Hall, J. E.; Pike, E. B.; Smith, S. R.; Unwin, R. J.; Review of the scientific evidence relating to the controls on the agricultural use of sewage sludge, WRc: Medmenham, 1998.

46. Borges, E. S. M.; Godinho, V. M.; Bejar, D. O.; Chernicharo, C. A.; Eng. Sanit. Ambient. 2009, 14, 337.

47. Navarro, G.; Química agrícola. El suelo y los elementos esenciales para la vida vegetal, Mundi prensa libros: Madrid, 2003. 